\title{
Hypoallergenicity of a New Extensively Hydrolyzed 100\% Whey-based Formula Containing Probiotics
}

\author{
Anna Nowak-Węgrzyn ${ }^{1}$, Laura A Czerkies ${ }^{2 *}$, Heidi M Storm ${ }^{2}$, Rosa Real ${ }^{2}$, Barbara Collins ${ }^{3}$ and José M Saavedra ${ }^{4}$ \\ ${ }^{1}$ Icahn School of Medicine at Mount Sinai, Division of Pediatric Allergy and Immunology, Jaffe Food Allergy Institute, New York, USA \\ ${ }^{2}$ Nestlé Nutrition, Florham Park, NJ, USA \\ ${ }^{3}$ Clinipace Worldwide, Morrisville, NC, USA \\ ${ }^{4}$ Nestlé Nutrition, Vevey, Switzerland
}

*Corresponding author: Saavedra JM, Nestle' Nutrition, Vevey, Switzerland. Tel: +4121924 6979; Email: jose.saavedra@nestle.com

Received date: August 12, 2015; Accepted date: August 28, 2015; Published date: September 04, 2015

Copyright: ( 2015 Nowak-Węgrzyn A, et al. This is an open-access article distributed under the terms of the Creative Commons Attribution License, which permits unrestricted use, distribution, and reproduction in any medium, provided the original author and source are credited.

\begin{abstract}
Objective: The American Academy of Pediatrics (AAP) defined an infant formula as hypoallergenic if it ensures with $95 \%$ confidence that $90 \%$ of infants/children with confirmed cow's milk protein allergy (CMA) do not react under double-blind, placebo-controlled conditions. The aim of this study was to determine whether a new $100 \%$ whey protein extensively hydrolyzed formula containing $B$. lactis CNCM I-3446, meets AAP hypoallergenicity criteria.

Methods: Children with CMPA were randomized to double-blind placebo-controlled food challenges (DBPCFC) with a new extensively hydrolyzed formula (Test) and a commercial extensively hydrolyzed formula (Control) in a cross-over fashion. CMPA was confirmed by elevated serum cow's milk (CM)-lgE levels, positive skin prick test to $\mathrm{CM}$ extract, or positive $\mathrm{CM}$ oral challenge within 6 months prior to enrollment. Allergic reactions in the DBPCFC's were assessed using a comprehensive scoring system. If both challenges were tolerated, subjects participated in an at-home week-long Test open challenge.

Results: Seventy-seven children $(3.30 \pm 2.98$ years old) with recently confirmed CMPA were enrolled. Of the 68 subjects participating in the Test DBPCFC, one had an allergic reaction (lower bound 95\% confidence interval of 0.921 for Test), while 4 out of 75 subjects participating in the DBPCFC with Control had an allergic reaction. The Test formula met the AAP hypoallergenicity criteria. Average formula intake during the Test open challenge was $250 \mathrm{ml} /$ day. One 6-year old subject reported angioedema, atopic dermatitis, rash around the eyes, and red swollen eyes on open challenge Day 6. This subject did not report any symptoms during the Test DBPCFC, was not exclusively formula-fed during the open challenge, and did not discontinue formula during the open challenge.

Conclusion: The new Test EHF meets the AAP criteria for hypoallergenicity and can be recommended for the management of CMPA.
\end{abstract}

Keywords: Cow's milk allergy; Infant formula; Extensively hydrolyzed; Whey; Hypoallergenic; Food allergy; Food challenge

\section{Introduction}

Cow's milk protein is the leading food allergen in infants and young children younger than 3 years [1-3]. The prevalence of cow's milk protein allergy (CMPA) has been reported to range from $0.9 \%$ up to as high as $17 \%$ worldwide. In an extensive meta-analysis on food allergy prevalence conducted by Rona and colleagues, prevalence of selfreported cow's milk hypersensitivity ranged from $1.2 \%$ to $17 \%$ [3]. The National Institute of Allergy and Infectious Diseases [4] report a CMPA prevalence of 3\% for all ages, and 6-7\% specifically for children, relying upon the work of Rona and colleagues [3]. Despite the heterogeneity in numbers reported (which was also seen for other foods), the literature still indicates food allergies as a growing issue worldwide that impacts quality of life. The allergic reactions that can occur following intact cow's milk protein ingestion vary from cutaneous symptoms, to GI symptoms, respiratory symptoms and severe anaphylaxis.
While breast milk is the optimal source of nutrition for infants through the first year of life, infants with CMPA who consume infant formula, as a supplement to breast milk or as sole source of nutrition may require infant formulas not including intact cow's milk protein. In non-breastfed infants and children less than 2 years of age with CMPA, dietary management with an appropriate substitute formula is necessary [5-8]. The American Academy of Pediatrics (AAP) recommends the use of a hypoallergenic infant formula in nonbreastfed infants with existing allergic symptoms [9]. A formula can be considered 'hypoallergenic' if at a minimum, it has been shown to ensure with $95 \%$ confidence that $90 \%$ of infants with documented CMPA will not react with defined symptoms to the formula under double-blind, placebo-controlled conditions [9]. Extensively hydrolyzed infant formulas use cow's milk protein as their protein source; however, unlike standard infant formulas, they undergo processing where the protein is broken down to smaller peptides with molecular weights lower than the intact protein, minimizing predominantly IgE-binding allergenic epitopes that could cause immediate allergic reactions in CMPA infants. The AAP describes an 
extensively hydrolyzed formula as containing only peptides that have a molecular weight of less than 3000 daltons [10].

A new extensively hydrolyzed, formula with $100 \%$ of protein in the form of whey proteins, designed for the management of cow's milk allergy, has been developed. This extensively hydrolyzed formula contains medium chain triglycerides (MCTs) that may enhance lipid absorption and a carbohydrate source blend with maltodextrin and potato starch that are easy to digest and do not contribute significantly to formula osmolality. The hydrolysate used in the new formula contains approximately $20 \%$ of protein in the form of free amino acids and $80 \%$ as small peptides. The majority of the peptides consist of 2,3 and 4 amino acids residues. The new extensively hydrolyzed formula also contains probiotic, $10^{6} \mathrm{CFU} / \mathrm{g}$ of Bifidobacterium lactis $\mathrm{CNCM}$ I-3446. The aim of this study was to determine whether this new formula meets the AAP hypoallergenicity criteria.

\section{Methods}

Infants and children of any ethnicity between 2 months and 12 years of age with documented CMPA who were otherwise healthy were recruited from 6 sites around the United States from August to September 2012. For the purpose of this study, all sites adhered to the clinical practice criteria established at Icahn School of Medicine at Mount Sinai, Division of Pediatric Allergy and Immunology (New York, New York). CMPA had to be documented within 6 months prior to enrollment by either: 1) reported convincing allergic symptoms following an exposure to milk or a milk-containing food product and detectable serum milk-specific IgE ( $>0.7 \mathrm{kIU} / \mathrm{L})$ or positive skin prick test (wheal greater than or equal to $5 \mathrm{~mm}$ ); or 2) physician-supervised oral food challenge that elicited immediate allergic symptoms; or 3) serum milk IgE $\geq 15$ [kIU/L]or $\geq 5$ [kIU/L if younger than 1 year; or 4 ) skin prick tests mean wheal $>10 \mathrm{~mm}$ [11-13]. All subjects were following a strict milk elimination diet at the time of enrollment and during the study. Potential subjects were excluded from study inclusion if they were consuming mother's milk at the time of study enrollment; had any chronic medical diseases, chromosomal or major congenital anomalies or major gastrointestinal disease/abnormalities (other than CMPA); had immunodeficiency; anti-histamine (not eye drops) use in 7 days prior to a food challenge, or oral steroid use within 14 days prior to enrollment; unstable asthma; severe uncontrolled eczema or severe anaphylactic reaction (requiring $\geq 2$ doses of epinephrine) to milk or breast milk within the last two years; and/or current participation in another clinical study.

Subjects were asked to complete double-blind, placebo controlled food challenges (DBPCFC) with both the test $100 \%$ whey extensively hydrolyzed formula with Bifidobacterium lactis (Gerber ${ }^{\circledR}$ Extensive $\mathrm{HA}^{\mathrm{n}}{ }^{\mathrm{m}}$, Nestlé Nutrition) and a control extensively hydrolyzed formula that was casein-based and contained the probiotic Lactobacillus LGG (Nutramigen $^{\circledR}$ with Enflora ${ }^{\mathrm{m}}$ LGG $^{\oplus}$, Mead Johnson ${ }^{\mathrm{Tm}}$ Nutrition) in a randomized, blinded, cross-over fashion. The macronutrient and micronutrient profiles of both formulas were similar (Table 1). The Test and the Control product were given in random order via a DBPCFC, with the first challenge within 5-9 days after enrollment and the second challenge within 2-7 days after the first challenge. Subjects were asked to fast for 1 hour prior to each DBPCFC session with allowance for light meals 2 hours prior to each session. For subjects $\leq 1$ year of age, the initial dose was a lip smear with the assigned formula, followed by $5 \mathrm{ml}, 10 \mathrm{ml}, 20 \mathrm{ml}, 30 \mathrm{ml}, 30 \mathrm{ml}, 35 \mathrm{ml}$, and $50 \mathrm{ml}$ at $10-15$ minute intervals. For subjects $>1$ year of age, the initial dose was a lip smear with the assigned formula, followed by $5 \mathrm{ml}, 10 \mathrm{ml}, 25 \mathrm{ml}, 45 \mathrm{ml}, 45$ $\mathrm{ml}, 45 \mathrm{ml}$ and $65 \mathrm{ml}$ at $10-15$ minute intervals. The total volume ingested was $180 \mathrm{ml}$ for subjects' $\leq 1$ year and $240 \mathrm{ml}$ for subjects $>1$ year. A minimum post-observation period of 1 hour was required. Each site followed its own clinical and safety monitoring standards of procedure throughout the DBPCFCs. All sites documented any allergic signs or symptoms (skin, gastrointestinal, respiratory, cardiovascular) attributable to test or control formulas on a standardized DBPCFC data collection form and adhered to a common definition of the criteria for the pass/fail for each symptom during the DBPCFC, as per recommendations of the Adverse Reactions to Food Committee of the American Academy of Allergy, Asthma and Immunology [19]. The two DBPCFCs occurred 2-7 days apart. Subjects were instructed to follow a cow's milk-free diet for the entire study period and provided with emergency treatment plan.

\begin{tabular}{|c|c|c|}
\hline & Control Formula & Test Formula \\
\hline Protein source & Casein, extensively hydrolyzed & $\begin{array}{l}\text { Whey, extensively } \\
\text { hydrolyzed }\end{array}$ \\
\hline $\begin{array}{l}\text { Protein } \\
\text { g/100 kcal (\% } \\
\text { kcal) }\end{array}$ & $2.8(11 \%)$ & $2.7(11 \%)$ \\
\hline Fat source & $\begin{array}{l}\text { Palm olein, soy oil, coconut oil, } \\
\text { high oleic sunflower oil, } \\
\text { docosahexaenoic acid (DHA), } \\
\text { arachidonic acid (ARA) }\end{array}$ & $\begin{array}{l}\text { Medium chain } \\
\text { triglycerides, soybean } \\
\text { oil, high oleic sunflower } \\
\text { oil, high sn-2-palmitate } \\
\text { palm oil, DHA, ARA }\end{array}$ \\
\hline $\begin{array}{l}\text { Fat } \\
\text { g/100 kcal (\% } \\
\text { kcal) }\end{array}$ & $5.3(48 \%)$ & $5(45 \%)$ \\
\hline $\begin{array}{l}\text { Carbohydrate } \\
\text { source }\end{array}$ & $\begin{array}{l}\text { Corn syrup solids, modified corn } \\
\text { starch }\end{array}$ & $\begin{array}{l}\text { Maltodextrin, potato } \\
\text { starch }\end{array}$ \\
\hline $\begin{array}{l}\text { Carbohydrate } \\
\text { g/100 kcal (\% } \\
\text { kcal) }\end{array}$ & $10.3(41 \%)$ & $10.7(43 \%)$ \\
\hline B. lactis & --- & $10^{6} \mathrm{cfu} / \mathrm{g}$ \\
\hline Lactobacillus GG & $10^{6} \mathrm{cfu} / \mathrm{g}$ & --- \\
\hline
\end{tabular}

Table 1: Macronutrient comparison.

The study protocol was approved by Copernicus Institutional Review Board (IRB) and the Icahn School of Medicine at Mount Sinai IRB. Informed consent was obtained from the parents of the participating children, and child's assent was documented as appropriate. Good clinical practice was followed by all sites throughout the study.

If a subject passed (had no allergic reaction) both DBPCFCs, s/he was eligible to participate in the open challenge. The subject was given the Test formula and instructed to drink a minimum of 8 ounces daily for a period of one week (7-9 days). Subjects were provided with an emergency plan for any adverse reactions. Daily formula intake was recorded as well as daily stool frequency, color, consistency, or odor; frequency of flatulence; frequency of spit-up and/or vomiting; any symptoms of potential allergic etiology; and any adverse or serious adverse events. 
Page 3 of 6

\section{Statistics}

The primary objective of this clinical trial was to determine whether a new extensively hydrolyzed whey-based formula met the AAP [9] criteria for hypoallergenicity, demonstrating with $95 \%$ confidence that $90 \%$ of infants or children with confirmed cow's milk allergy will not develop allergic reactions based on a double-blinded, placebocontrolled food challenge. Basically, if the lower bound of the onesided exact 95\% confidence interval (CI) for the proportion of subjects without allergic reactions at the end of the study was at least $90 \%$, hypoallergenicity of the Test formula was demonstrated. The number and percentage of subjects with no allergic reactions are presented by formula group (Test and Control). One-sided 95\% exact CI is provided for the point estimates of the proportion of subjects with no allergic reactions by formula. Baseline and demographic characteristics are summarized using the number of subjects, mean, standard deviation, and median, minimum, maximum.

A total of 66 subjects were chosen which would allow for 2 reactions to the Test formula to still meet the AAP hypoallergenicity criteria. An interim analysis was planned after 35 subjects had completed both periods. If there were no allergic reactions observed to the Test formula after 35 subjects, the adjusted one-sided exact lower bound CI would have been at least $90.1 \%$ which meets the standard specified by the AAP. If more than 2 reactions had been observed to the Test formula, a minimum adjusted one-sided exact lower bound CI of $90 \%$ could not have been reached. The maximum adjusted sample size assuming a linear spending function with one interim analysis at information fraction $\mathrm{t}=0.53(35 / 66)$ was 66 .

Three analysis populations were used in this study. The Intention to Treat (ITT) population was defined as all randomized subjects who took any amount of the study formula. The modified ITT population (mITT) was defined as all randomized subjects who took any amount of Test or Control formula and had documented CMPA at the time of the food challenges. A subject was included in the per protocol (PP) population as long as both DBPCFCs for that subject were completed. The determination of AAP criteria was based on the mITT and PP populations.

For the 1-week open challenge with the Test formula, descriptive statistics were performed to describe intake, stool characteristics, and frequency of vomit. All statistical analysis was performed using SAS statistical software (Version 8.2).

\section{Results}

In total, 80 subjects were consented to be in the study and were included in the Intention-to-Treat (ITT) population. It was later determined that three of these subjects did not have confirmed CMPA within 6 months of enrollment, and these subjects were excluded from the analysis; this population was defined as the modified ITT population (mITT; $n=77$ ). Demographics of the mITT population are presented in Table 2. The majority of subjects were between the ages of 1 and 5 years old, with the overall average of 3.35 years. Most subjects were male and were predominantly Caucasian.

Study formulas were originally coded to green and yellow, with the allocation of test and control to these colors being blinded. An interim analysis was performed after 44 subjects had completed the study as 3 subjects had reacted to the yellow formula. At this point, one subject had reacted to the green formula. The study was unblinded, and it was revealed that 3 reactions had occurred in the Control group and one in the Test group. Therefore, the study continued with the study formulas being coded with different colors to maintain the study blind.

\begin{tabular}{|l|l|}
\hline & Study Population (n=77) \\
\hline Age at Enrollment (years) & $3.30 \pm 2.98$ \\
\hline$<1$ year & $10(13 \%)$ \\
\hline $1-5$ years & $50(64.9 \%)$ \\
\hline $6-12$ years & $17(22.1 \%)$ \\
\hline Males:Females & $51: 26(66.2 \%: 33.8 \%)$ \\
\hline $\begin{array}{l}\text { Diagnostic Criteria } \\
\text { Reported convincing allergic symptoms following } \\
\text { an exposure to milk /milk-containing food product } \\
\text { and serum milk-specific IgE (>0.7 kIU/L) or positive } \\
\text { skin prick test (wheal>5 mm) }\end{array}$ & $55(71.4 \%)$ \\
\hline $\begin{array}{l}\text { Results of laboratory tests highly predictive of } \\
\text { clinical reactivity to milk by serum milk lgE>15 } \\
\text { klU/L }\end{array}$ & $9(11.7 \%)$ \\
\hline $\begin{array}{l}\text { Results of laboratory tests highly predictive of } \\
\text { clinical reactivity to milk by skin prick test } \\
\text { (wheal>10 mm) }\end{array}$ & $13(16.9 \%)$ \\
\hline
\end{tabular}

Table 2: Summary of subject demographic and baseline characteristics (mITT population).

Of the 77 subjects in the mITT population who consumed any amount of a formula during a DBPCFC, 68/77 subjects participated in the Test DBPCFC (Figure 1). Nine of these subjects did not participate in the Test DPBCFC because 6 of them dropped during the Control DBPCFC due to the dislike of the formula taste and did not return for the Test DBPCFC (majority of these subjects dropped before $10 \mathrm{ml}$ dose); 2 others failed the Control DBPCFC and did not return for the Test DBPCFC; and 1 additional subject had passed the Control DBPCFC, but did not return for the Test DBPCFC. Seventy-five subjects participated in the Control DBPCFC; 2 did not participate in the Control DBPCFC because 1 subject dropped during the Test DBPCFC due to formula taste after the $5 \mathrm{ml}$ dose and did not return for the Control DBPCFC, and the other subject failed the Test DBPCFC and did not return for the Control DBPCFC.

One of 68 subjects had an allergic reaction during the DBPCFC with Test (lower bound 95\% confidence interval of 0.921 for Test); therefore, meeting the AAP hypoallergenicity criteria. This 2-year-old subject had a positive reaction to the Test formula at the subject's first visit (itchy mouth, nausea, abdominal pain, vomit 3 times) after consuming $65 \mathrm{ml}$ of Test product. This subject did not return for the second visit where a DBPCFC with the Control product would have occurred. Four subjects had a positive reaction to the Control formula. Two of these subjects were randomized to receive the Control formula first: one was 2 years old and after consuming $40 \mathrm{ml}$ of Control product, had developed erythema, severe generalized urticaria, and macular and raised rash; the other was a 7.5 year-old who had mild urticaria and rhinorrhea, 1 episode of emesis or diarrhea, color change, mental status change, tachycardia, frequent complaints of nausea or pain, and decreased activity after consuming a total of $125 \mathrm{ml}$ of Control formula. After their failed DBPCFC, neither of these subjects returned for the second visit where the Test formula would have been given. A third 12-year-old subject who was also randomized to receive the 
Page 4 of 6

Control formula first and failed the DBPCFC after consuming a total of $85 \mathrm{ml}$ (hives on leg, continued complaints of itchy mouth, nausea, abdominal pain) did return for the second visit where the DBPCFC with the Test formula was passed. The fourth 4-year-old subject was randomized to receive the Test formula first and passed this DBPCFC. At the second visit, this subject failed the DBPCFC after consuming 15 $\mathrm{ml}$ of Control formula (mild, occasional scratching; moderate urticaria/angioedema; mild sneezing/itching; mild nasal congestion; moderate rhinorrhea; moderate hoarseness, frequent dry cough). A summary of the number of subjects who did or did not have reactions during DBPCFCs is presented in Table 3.

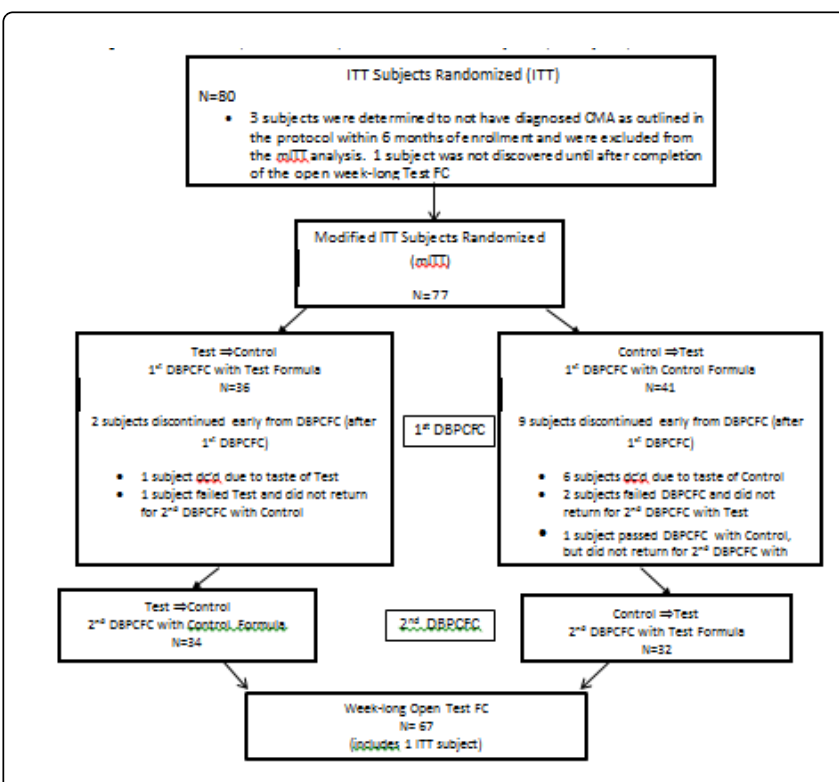

Figure 1: Study schematic.

In total, 66 subjects completed both the DBPCFC with the Test and Control formulas and were considered part of the PP population. Of these 66 , no subjects had a reaction to the Test formula $(0 \%, 0.946$ lower bound $95 \%$ confidence interval). Two of the 66 subjects had a reaction to the Control formula (3\%; 0.895 lower bound 95\% confidence interval).

Sixty-five subjects were eligible to participate in the week-long open challenge of the Test formula. This included the 64 subjects in the PP population who did not have a reaction to both the Test and Control formulas during the DBPCFCs and 1 of the subjects in the ITT population who was not diagnosed with CMPA within 6 months of enrollment; however, this was not determined until after the subject completed the open challenge. Of the 65,44 consumed a minimum of $8 \mathrm{oz}$ of formula/day for a week. No unusual stool patterns, consistency, or odor were reported. One subject reported vomiting on Day 1, Day 3 and Day 6 of the open challenge. Six subjects reported symptoms of potential allergic etiology (seasonal pollen allergy; wheezing; emesis, diarrhea, cough; gastritis; mild rash; rash and redness around eyes). Only one out of the six subjects reported the symptoms as an adverse event with causal relationship of "certain" according to the Investigator to the Test formula; this subject reported rash and redness around the eyes as a symptom of potential allergic etiology beginning on the $6^{\text {th }}$ day of the subject's open challenge. The formula was not discontinued and the symptoms were reported to have resolved after 6 days. The subject was given prednisolone.

\begin{tabular}{|c|c|c|c|c|}
\hline & Visit $1 \mathrm{n}(\%)$ & $\begin{array}{ll}\text { Visit } 2 & n \\
(\%) & \end{array}$ & $\begin{array}{l}\text { Overall } n \\
(\%)\end{array}$ & $\begin{array}{l}95 \% \text { confidence interval } \\
\text { lower bound }\end{array}$ \\
\hline \multicolumn{5}{|c|}{ Subject has any allergic reaction? } \\
\hline \multicolumn{5}{|c|}{ Test Formula } \\
\hline Yes & $1(2.8 \%)$ & $0(0.0 \%)$ & $1(1.5 \%)$ & \multirow[t]{2}{*}{$0.921(92.1 \%)$} \\
\hline No & $\begin{array}{l}35 \\
(97.2 \%)\end{array}$ & $32(100 \%)$ & $67(98.5 \%)$ & \\
\hline \multicolumn{5}{|c|}{ Control Formula } \\
\hline Yes & $3(7.3 \%)$ & $1(2.9 \%)$ & $4(5.3 \%)$ & \multirow[t]{2}{*}{$0.869(86.9 \%)$} \\
\hline No & $\begin{array}{l}38 \\
(92.7 \%)\end{array}$ & $33(97.1 \%)$ & $71(94.7 \%)$ & \\
\hline
\end{tabular}

Table 3: Summary of subjects with allergic reactions (Yes/No) by formula and visit (mITT population, defined as any subject who consumed any amount of formula during the DBPCFC).

\section{Discussion}

Hypoallergenic infant formulas are intended for use by infants with cow's milk allergy. For an infant formula to be considered hypoallergenic, the AAP developed guidelines and recommendations. This clinical study demonstrated that the new $100 \%$ whey extensively hydrolyzed Test formula meets AAP hypoallergenicity criteria. With 1 out of 68 subjects showing a reaction to the Test formula, the lower bound $95 \%$ confidence interval was 0.921 (92.1\%) which is greater than the required 0.90 level for the AAP criteria of hypoallergenicity of a formula. The reaction to the Test formula happened during the subject's first DBPCFC visit, and this subject did not return for the DBPCFC of the Control formula. Therefore, it is unknown whether this subject would have also reacted to the Control formula. During the open challenge, 44 subjects out of 65 participating subjects were able to consume a minimum of $8 \mathrm{oz}$. of the Test formula on a daily basis. The Test formula was generally well-tolerated. One subject did report redness around the eyes and a rash on the 6th day with the investigator citing a 'certain' relationship to the study formula. However, the symptoms resolved, and at no point did the subject stop the study formula.

In this study, a total of 5 subjects did have an allergic reaction to the extensively hydrolyzed formulas used ( 1 reaction to Test formula, 4 reactions to Control formula). Other reactions to extensively hydrolyzed formulas have been documented [14-16]. The AAP acknowledges that at least $90 \%$ of infants and children with CMPA tolerate extensively hydrolyzed formulas as well as the more recently introduced free amino acid-based infant formulas. It has been estimated that approximately $10 \%$ of children with CMPA may react to $\mathrm{EHF}$, and amino acid-based formulas would be necessary for this population [9].

A unique feature of the Test formula is the presence of Bifidobacterium lactis, which has been shown to increase fecal secretory IgA in infants [17] and children [18]. In situations where an exclusively formula-fed infant with confirmed or suspected allergy to milk protein is required to avoid the offending antigen (cow's milk protein), the elimination diet is not only free of intact cow's milk protein, but also void of lactose which is bifdogenic by nature. In a study [19] of 46 infants with IgE-mediated CMPA, fecal samples were obtained at the time of diagnosis (median age of 4.3 months) and after 
6 months follow-up. After diagnosis, subjects began to consume an extensively hydrolyzed infant formula without lactose, or pre- or probiotics. A group of 46 age-matched healthy controls who began formula-feeding at similar ages also provided fecal samples at the same time-points. Fecal samples were cultured for aerobes, anaerobes, enterobacteria, clostridia, bifidobacteria, lactobacilli, and yeasts. At baseline, no differences were seen in any of the cultured bacterial groups. However, at 6 months, the CMPA group had a higher proportion of lactobacilli $(\mathrm{p}=0.001)$ and lower proportions of enterobacteria $(p=0.003)$, bifidobacteria $(p<0.001)$ and yeasts $(p<0.001)$ compared with healthy controls. It is interesting to note that no differences were seen at the time of diagnosis, but that after 6 months of feeding with an infant formula without pre- or probiotics, significant differences were seen. Although the contribution of CMPA to the noted observations during the 6 month period is unknown, the reported microbial changes may be attributed, at least in part, to the dietary matrix which was lactose-free. Optimal patterns of gut colonization to promote establishment of tolerance have not been defined; however, efforts to modify the microbiota of allergic infants to be more like that of their healthy, non-allergic counterparts may be advantageous, particularly in the absence of dietary lactose. The addition of probiotics like $B$. lactis to extensively hydrolyzed whey formula could provide an infant with CMPA a source of beneficial bacteria that could promote a more balanced microbiota.

In general, extensively hydrolyzed infant formulas have a distinct taste and odor due to the peptides resulting from the hydrolysis process. In this study, level of acceptance of the Test formula was greater as 1 out of 68 subjects (1.5\%) who drank any amount of Test formula during the DBPCFC dropped out due to taste while 6 out of 75 (8\%) who drank any amount of Control formula during the DBPCFC discontinued due to taste of the formula. The subjects who dropped out of a DBPCFC due to taste were all over 18 months of age. If an infant is started early on in life with an extensively hydrolyzed formula, acceptance of the distinct taste may not be an issue. Results of this study indicate a higher level of acceptance of the Test formula as compared to the Control formula in children with CMPA.

Extensively hydrolyzed whey formulas have been studied in children with CMPA for over 30 years. In a study by Niggeman and colleagues, 66 infants with confirmed CMPA completed double-blind placebocontrolled food challenges (DBPCFCs) with a whey-based extensively hydrolyzed formula (Althera', Nestlé Nutrition, Vevey, Switzerland) and an amino acid-based formula (Neocate', Nutricia, Liverpool, England), in random order [20]. Subjects also completed skin prick tests with both of these formulas. None of the subjects had a positive allergic reaction to either formula, demonstrating that Althera met the AAP criteria for hypoallergenicity. None of the subjects had a positive skin prick test to either of the formulas. For the second phase of the study, subjects were randomized to receive either Althera or Neocate for a period of 6 months, where growth and tolerance symptoms were evaluated. There were no significant differences between the two groups in any growth parameter, and gastrointestinal and respiratory symptoms of allergy were comparable [20]. In a study by Vandenplas and colleagues [21], 116 infants with suspected CMPA were randomized to receive either an extensively hydrolyzed casein formula with a probiotic (Lactobacillus LGG) or an extensively hydrolyzed whey formula with a probiotic (B. lactis) for a period of 1 month. After 1 month of feeding, subjects completed an open food challenge to diagnose CMPA. If the subject was found to have CMPA, the randomized formula was continued to 1 year of age; in those who did not have CMPA, a standard, intact cow's milk-based formula was given. Allergy symptoms improved in both groups over time; no differences were seen in stool characteristics between the two groups.

In conclusion, the primary objective of this study was met; the Test formula was demonstrated to meet the AAP-defined criteria for hypoallergenicity of a formula. Extensively hydrolyzed 100\% whey formula with probiotic Bifidobacterium lactis offers another safe option for infants and children with CMPA who require the use of a hypoallergenic formula.

\section{Acknowledgement}

The authors thank the study staff and investigators for their cooperation. The participation of the parents, guardians, infants, and children in this study is also acknowledged. Finally, the authors acknowledge Clinipace for their role as the Contract Research Organization for study execution.

\section{References}

1. Gupta RD, Springston EE, Warrier MR, Smith B, Kumar R, et al (2011) The prevalence, severity and distribution of childhood food allergy in the United States. Pediatrics 128: e9-17.

2. Rona RJ, Keil T, Summers C, Gislason D, Zuidmeer L, et al (2007) The prevalence of food allergy: a meta-analysis. J Allergy Clin Immunol 120: 638-646.

3. Burks AE, Jones SM, Boyce JA, Sicherer SH, Wood RA, et al (2011) NIAID-sponsored 2010 guidelines for managing food allergy; applications in the pediatric population. Pediatrics 128: 955-965.

4. Groetch M, Nowak-Wegrzyn A (2013) Practical approach to nutrition and dietary intervention in pediatric food allergy. Pediatr Allergy Immunol 24: 212-221.

5. Fiocchi A, Brozek J, Schünemann H, Bahna SL, von Berg A, et al (2010) World Allergy Organization (WAO) Diagnosis and Rationale for Action against Cow's Milk Allergy (DRACMA) Guidelines. Pediatr Allergy Immunol 21: 1-125.

6. Muraro A, Werfel T, Hoffmann-Sommergruber K, Roberts G, Beyer K, et al. (2014) EAACI food allergy and anaphylaxis guidelines: diagnosis and management of food allergy. Allergy 69: 1008-1025.

7. Sampson HA, Aceves S, Bock SA, James J, Jones S, et al. (2014) Food allergy: a practice parameter update-2014. The Journal of Allergy and Clinical Immunology 134: 1016-1025.e43.

8. (2000) American Academy of Pediatrics. Committee on Nutrition. Hypoallergenic infant formulas. Pediatrics 106 (2 pt 1): 346-349.

9. Greer FR, Sicherer SH, Burks AW; American Academy of Pediatrics Committee on Nutrition; American Academy of Pediatrics Section on Allergy and Immunology (2008) Effects of early nutritional interventions on the development of atopic disease in infants and children: the role of maternal dietary restriction, breastfeeding, timing of introduction of complementary foods, and hydrolyzed formulas. Pediatrics 121: 183-191.

10. Sporik R, Hill DJ, Hosking CS (2000) Specificity of allergen skin testing in predicting positive open food challenges to milk, egg and peanut in children. Clin Exp Allergy 30: 1540-1546.

11. Sampson HA (2001) Utility of food-specific $\operatorname{IgE}$ concentrations in predicting symptomatic food allergy. J Allergy Clin Immunol 107: 891-896.

12. Garcia-Ara C, Boyano-Martinez T, Diaz-Pena JM, Martin-Munoz F, Reche-Frutos M, et al. (2001) Specific IgE levels in the diagnosis of immediate hypersensitivity to cows' milk protein in the infant. J Allergy Clin Immunol 107: 185-190.

13. de Boissieu D, Matarazzo P, Dupont C (1997) Allergy to extensively hydrolyzed cow milk proteins in infants: identification and treatment with an amino acid-based formula. J Pediatr 131: 744-747.

14. Hill DJ, Cameron DJ, Francis DE, Gonzalez-Andaya AM, Hosking CS (1995) Challenge confirmation of late-onset reactions to extensively 
Citation: $\quad$ Nowak-Wegrzyn A, Czerkies LA, Storm HM, Real R, Collins B, et al. (2015) Hypoallergenicity of a New Extensively Hydrolyzed 100\% Whey-based Formula Containing Probiotics. J Allergy Ther 6: 221. doi:10.4172/2155-6121.1000221

Page 6 of 6

hydrolyzed formulas in infants with multiple food protein intolerance. Allergy Clin Immunol 96: 386-394.

15. Saylor JD, Bahna SL (1991) Anaphylaxis to casein hydrolysate formula. J Pediatr 118: 71-74.

16. Holscher HD, Czerkies LA, Cekola P, Litov R, Benbow M, et al. (2012) Bifidobacterium lactis Bb12 enhances intestinal antibody response in formula-fed infants: a randomized, double-blind, controlled trial. J Parenter Enteral Nutr 36: 106S-17S.

17. Fukushima Y, Kawata Y, Hara H, Terada A, Mitsuoka T (1998) Effect of a probiotic formula on intestinal immunoglobulin A production in healthy children. Int J Food Microbiol 42: 39-44.
18. Thompson-Chagoyan OC, Vieites JM, Maldonado J, Edwards C, Gil A (2010) Changes in faecal microbiota of infants with cow's milk protein allergy--a Spanish prospective case-control 6-month follow-up study. Pediatr Allergy Immunol 21(2 Pt 2): e394-400.

19. Niggemann B, von Berg A, Bollrath C, Berdel D, Schauer U, et al. (2008) Safety and efficacy of a new extensively hydrolyzed formula for infants with cow's milk protein allergy. Pediatr Allergy Immunol 19: 348-354.

20. Vandenplas Y, Steenhout P, Planoudis Y, Grathwohl D; Althera Study Group (2013) Treating cow's milk protein allergy: a double-blind randomized trial comparing two extensively hydrolysed formulas with probiotics. Acta Paediatrica 102: 990-998. 